https://doi.org/10.15407/ujpe64.4.340

O.M. ALEKSEEV,${ }^{1}$ S.O. ALEKSEEV,${ }^{1}$ YU.F. ZABASHTA,${ }^{1}$ M.M. LAZARENKO, ${ }^{1}$ K.I. HNATIUK, ${ }^{1}$ M.V. LAZARENKO ${ }^{2}$ R.V. DINZHOS ${ }^{3}$ M.S. SIMEONOV ${ }^{4}$

1 Taras Shevchenko National University of Kyiv, Faculty of Physics, Chair of Molecular Physics (6, Academician Glushkov Ave., Kyiv 03022, Ukraine; e-mail: maxs@univ.kiev.ua)

2 National University of Food Technologies (68, Volodymyrs'ka Str., Kyiv 01033, Ukraine)

3 V.O. Sukhomlynskyi Mykolayiv National University

(24, Nikols'ka Str., Mykolayiv 54030, Ukraine)

${ }^{4}$ St. Kliment Ohridski University of Sofia

(James Bourchier Blvd., Sofia 1164, Bulgaria)

\title{
INFLUENCE OF OPEN-POROUS SYSTEM ON THE SOLID-STATE PHASE TRANSITION IN 1-OCTADECENE
}

\begin{abstract}
The solid-state phase transition in the silica gel-1-octadecene system has been studied at various temperatures with the help of differential scanning calorimetry and FTIR spectroscopy. Silica gels KSK-2.5, KSS-4, and Silica Gel 60 with different surface parameters are used. The temperature of the solid-state phase transition in the silica gel-1-octadecene system is shown to linearly depend on the ratio between the pore surface area and the pore volume. The energy characteristics of 1-octadecene nanocrystals in the surface layer are calculated in the framework of a thermodynamical model of crystal melting in pores.

Keywords: solid-state phase transition, nanocrystals, porous silica gel.
\end{abstract}

\section{Introduction}

The properties of substances located in nano-sized pores play an essential role in the phenomena associated with clay swelling, soil frost heaving, oil production, colloidal stability, and drug transport through biomembranes [1]. The configuration of nanopores has a significant effect on the physical properties of solids in them [2-4]. In particular, the melting temperature and the temperature of solid-state phase transition are changed in nanocomposite materials [5]. The reduction of the melting temperature was considered in many works [1-5].

(C) O.M. ALEKSEEV, S.O. ALEKSEEV,

YU.F. ZABASHTA, M.M. LAZARENKO,

K.I. HNATIUK, M.V. LAZARENKO, R.V. DINZHOS,

M.S. SIMEONOV, 2019
The solid-state phase transition in systems of aliphatic molecules is a transition from the crystalline phase to the rotational one. The understanding of the mechanism of this phase transition has a large practical importance to the physics of condensed systems and materials science. The solid-state phase transition in such systems occurs at temperatures that are only a few degrees lower than the melting ones. This circumstance complicates its experimental research. Therefore, the number of publications where this transition was studied under confinement conditions is much less than the number of works dealing with the melting under the same conditions [6].

The microscopic mechanism of solid-state transitions in alkanes - both in bulk systems and in pores is not understood yet in full and requires to be studied further $[7,8]$. The influence of a nanopore morphol-

ISSN 2071-0194. Ukr. J. Phys. 2019. Vol. 64, No. 4 
ogy on this solid-state transition has to be analyzed as well.

In this work, the influence of the silica gel matrix morphology on the solid-state phase transition in 1-octadecene, $\mathrm{CH}_{3}\left(\mathrm{CH}_{2}\right)_{15} \mathrm{CH}=\mathrm{CH}_{2}$ (Fig. 1), has been studied. 1-octadecene belongs to the class of $\alpha$ olefins (they have an aliphatic chain), in which there is a methyl group $\left(-\mathrm{CH}_{3}\right)$ at one end and a vinyl one $\left(-\mathrm{CH}=\mathrm{CH}_{2}\right)$ at another one. The vinyl group can serve as a marker, when studying the thermal motion of an aliphatic molecule. A 1-octadecene molecule has 18 carbon atoms. When being cooled down, the substance concerned forms crystals created by straightened molecular chains, whose axes are oriented perpendicularly to the crystalline plane [9].

In our previous work [10], it was shown that, when being heated, bulk crystalline 1-octadecene undergoes the transition from the orthorhombic crystalline phase, $\mathrm{Or}_{\text {crys }}$, to the orthorhombic rotationalcrystalline one, $\mathrm{Or}_{\text {rot }}$. This is a phase transition of the first kind in the solid phase. At a further heating, the melting of the substance takes place.

Some researches concerning the influence of the pore morphology in silica gel on the melting of 1octadecene crystals were carried out in our previous works $[11,12]$. Owing to a small difference between the temperatures of indicated phase transitions, there arose a necessity to apply other experimental methods in order to correctly separate the contributions of those processes. In particular, IR spectra of $\mathrm{SiO}_{2}-1$ octadecene systems were registered in a wide temperature interval that included the indicated phase transitions [11]. The available structurally sensitive absorption bands allowed the temperature of each phase transition to be determined separately and more accurately.

The aim of this work is to study the phase transition in 1-octadecene in the solid state located in a porous silica gel matrix and experimentally determine the corresponding energy (the difference between the surface tensions of the crystalline and rotational phases) and entropy (the difference between the surface entropies of the crystalline and rotational phases) characteristics.

\section{Experimental Part}

\subsection{Research methods}

For the research of phase transformations, a differential scanning calorimeter DSC Q200 (TA Instru-

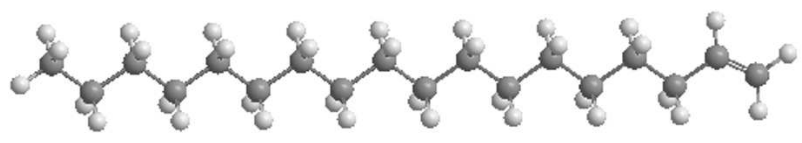

Fig. 1. Molecule of 1-octadecene

ments, USA) was used. The temperature calibration was carried out with the help of sapphire disks (supplied by TA Instruments) in standard aluminum crucibles. The studies were performed in the temperature interval from $-90{ }^{\circ} \mathrm{C}$ to $120^{\circ} \mathrm{C}$ at a heating rate of $5^{\circ} \mathrm{C} / \mathrm{min}$ in a nitrogen flux of $50 \mathrm{ml} / \mathrm{min}$. Infrared transmission spectra were registered on a NicoletNexus Fourier Infrared Spectrometer in the spectral interval $625-4000 \mathrm{~cm}^{-1}$ with a spectral resolution of $1 \mathrm{~cm}^{-1}$. The registration was carried out in the transmission mode immediately from the "free layer". In order to compare the intensities of absorption bands in the spectra, the following conditions were obeyed: (i) the size of the aperture, with respect to which the background spectrum was recorded, corresponded to the size of the specimen, so that the specimen completely covered the aperture, and (ii) the sensitivity intervals of the device were identical, when recording the background and specimen spectra. The spectra were recorded in the temperature interval from $-150{ }^{\circ} \mathrm{C}$ to $50^{\circ} \mathrm{C}$ with the increment $\Delta T=5{ }^{\circ} \mathrm{C}$ in the transmission mode with the help of a Variable Temperature Cell P/N 21525 (Specac company) with the windows from sodium chloride. In the course of spectrum registration, the cell was pumped out by means of a backing pump. The specimens were first cooled down in liquid nitrogen. Then they were heated up at a rate of $2{ }^{\circ} \mathrm{C} / \mathrm{min}$, and the spectra were registered.

\subsection{Raw materials and specimen preparation}

Silica gels with various pore sizes were used. The specimen characteristics were determined by analyzing the nitrogen adsorption isotherms measured at $-196{ }^{\circ} \mathrm{C}$ on a high-vacuum adsorption device Sorptomatic 1990 (see Table 1 ).

To fill the silica gel pores with 1-octadecene, the silica gel specimens were embedded into the $20 \%$ solution of 1-octadecene in hexane. The indicated silica gel-to-solution ratio was so selected that 1-octadecene should fill $75-80 \%$ of the silica gel pore volume in the resulting composite. The mixtures of silica gel 

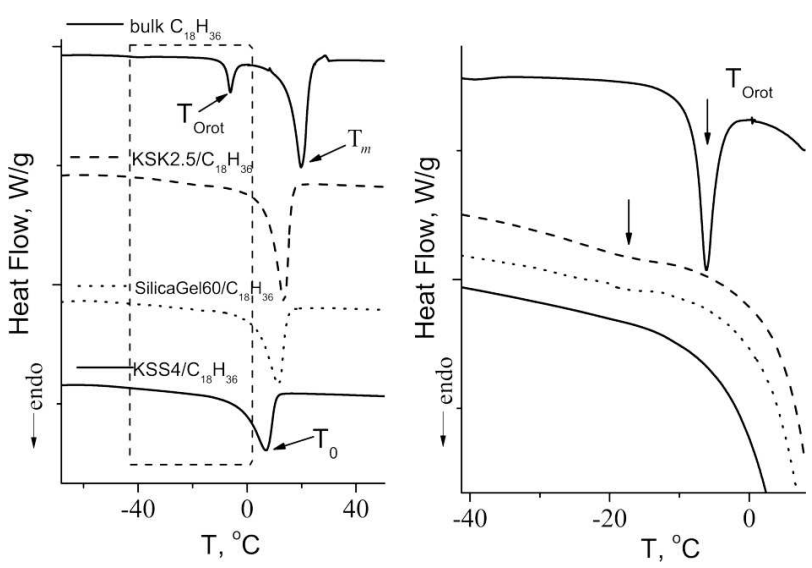

Fig. 2. Temperature dependences of the heat flux for examined specimens. $T_{\text {Orot }}$ is the temperature of the phase transition from the orthorhombic crystalline phase $\mathrm{Or}_{\text {crys }}$ into the orthorhombic rotational-crystalline phase $\mathrm{Or}_{\mathrm{rot}}, T_{m}$ the melting temperature of bulk 1-octadecene, and $T_{0}$ the melting temperature of 1-octadecene in silica gel pores

with 1-octadecene hexane solutions were irradiated with ultrasound in order to remove air remnants from the pores and then dried in air at a temperature of $90{ }^{\circ} \mathrm{C}$. The resulting specimens were loose powders, whose particles did not stick together. The latter fact confirmed that the total amount of 1-octadecene was absorbed into the pores of silica gel particles.

To determine the content of 1-octadecene in porous matrices, the thermogravimetric researches using a Derivatograph Q1500D device were performed. The results of those studies are quoted in Table 2. One can

Table 1. Parameters of porous silica gels

\begin{tabular}{|l|c|c|c|c|}
\hline \multicolumn{1}{|c|}{ Silica gels } & $V, \mathrm{~cm}^{3} \mathrm{~g}^{-1}$ & $S, \mathrm{~m}^{2} \mathrm{~g}^{-1}$ & $D, \mathrm{~nm}$ & $S / V, \mathrm{~nm}^{-1}$ \\
\hline KSK 2.5 & 0.926 & 311 & 11.93 & 0.33 \\
Silica Gel 60 & 0.755 & 426 & 7.10 & 0.56 \\
KSS 4 & 0.260 & 229 & 4.54 & 0.88 \\
\hline
\end{tabular}

Table 2. Contents of adsorbed

water, 1-octadecene, and surface - $\mathrm{OH}$ groups in specimens (in percent)

\begin{tabular}{|l|c|c|c|}
\hline \multicolumn{1}{|c|}{ Silica gels } & $m\left(\mathrm{H}_{2} \mathrm{O}\right)$ & $m$ (1-octadecene) & $m(-\mathrm{OH})$ \\
\hline KSK 2.5/ $\mathrm{C}_{18} \mathrm{H}_{36}$ & 2.3 & 32.3 & 5 \\
Silica Gel 60/ $\mathrm{C}_{18} \mathrm{H}_{36}$ & 3.3 & 32.1 & 3.4 \\
KSS 4/ ${ }_{18} \mathrm{H}_{36}$ & 4.7 & 22.4 & 4.3 \\
\hline
\end{tabular}

see that silica gel pores contained adsorbed moisture $\left(\mathrm{H}_{2} \mathrm{O}\right)$, 1-octadecene, and surface groups $-\mathrm{OH}$.

\subsection{Calorimetry}

We measured the temperature dependences of the thermal flux in bulk 1-octadecene and 1-octadecene in silica gel pores in a temperature interval from $-80{ }^{\circ} \mathrm{C}$ to $120{ }^{\circ} \mathrm{C}$ at a heating rate of $5{ }^{\circ} \mathrm{C} / \mathrm{min}$ (Fig. 2). In our previous research of bulk 1-octadecene, it was shown that if 1-octadecene polycrystals are heated, then, starting from a temperature of about $T_{\text {bOrot }}=$ $-30{ }^{\circ} \mathrm{C}$, they undergo the phase transition from the orthorhombic crystalline phase, $\mathrm{Or}_{\text {crys }}$, into the orthorhombic rotational-crystalline one, $\mathrm{Or}_{\text {rot }}$, with a maximum at $T_{\text {Orot }}=-6{ }^{\circ} \mathrm{C}$. This is a solid-phase transition of the first kind. When reaching the temperature $T_{b m}=0{ }^{\circ} \mathrm{C}$, 1-octadecene polycrystals begin to melt with a maximum at $T_{m}=20{ }^{\circ} \mathrm{C}$. At $T_{e m}=35^{\circ} \mathrm{C}$, the melting process comes to an end.

The temperature dependences of the heat flux obtained for nanostructured 1-octadecene in various porous silica gel matrices (Fig. 2) demonstrate the same phase transitions as in bulk 1-octadecene. One can see that the phase transition temperature decreases together with the pore size. Characteristic temperatures of the solid-phase transition $T_{\text {Orot }}$ can be determined from the temperature dependences of the heat flux, but only with a low accuracy. Therefore, the method of infrared spectroscopy of specimens was additionally applied at various temperatures.

\subsection{IR spectroscopy}

The infrared transmission spectra of 1-octadecene were registered at various temperatures (see Fig. 3). When 1-octadecene polycrystals are heated up, the band changes can be observed (i) in a region of $720 \mathrm{~cm}^{-1}$ corresponding to pendulum vibrations of $\mathrm{CH}_{2}$ groups $\left(\Delta \nu_{1,2}\right)$, (ii) in a region of $908 \mathrm{~cm}^{-1}$ corresponding to deformation vibrations of the double bond $-\mathrm{CH}=\mathrm{CH}_{2}\left(\nu_{\rho\left(=\mathrm{CH}_{2}\right)}\right)$, and (iii) in regions of 2845 and $2929 \mathrm{~cm}^{-1}$ (Fig. 3) corresponding to symmetric $\left(\nu_{s\left(-\mathrm{CH}_{2}\right)}\right)$ and antisymmetric $\left(\nu_{a s}\left(-\mathrm{CH}_{2}\right)\right)$ valence vibrations of $\mathrm{C}-\mathrm{H}$ groups [13].

One of the structurally sensitive bands in the IR spectrum of molecules with aliphatic chains is the band in a vicinity of $\nu=720 \mathrm{~cm}^{-1}$ stemming from pendulum vibrations of $\mathrm{CH}_{2}$ groups. At tempera- 
tures below the phase transition ones, this band is split by $\Delta \nu_{1,2}(T)$ (this is inherent only to the orthorhombic subcell of the $\mathrm{Or}_{\text {crys }}$ crystal [14]). Figure 3 demonstrates fragments of the IR spectra of bulk 1-octadecene registered at various temperatures. In the region of $\nu=720 \mathrm{~cm}^{-1}$, a splitting of the band is observed at the temperature $T=-80^{\circ} \mathrm{C}$. As the temperature grows, two peaks approach each other, and, in a vicinity of the phase transition, they merge into a single peak. To resolve the two maxima and determine the value of $\Delta \nu_{1,2}(T)$ in the region of $\nu=720 \mathrm{~cm}^{-1}$, we approximated the peak profiles by the Voigt distribution.

The temperature dependences of the splitting magnitude $\Delta \nu_{1,2}(T)$ for the band of pendulum vibrations of $\mathrm{CH}_{2}$ groups in a vicinity of $\nu=720 \mathrm{~cm}^{-1}$ are shown in Fig. 4 for bulk 1-octadecene and 1octadecene in various matrices. In order to determine the temperatures of the phase transitions more accurately, we plotted the temperature dependences of the splitting derivative with respect to the temperature, $d \nu / d T$. A typical dependence of $d \nu / d T$ on $T$ obtained for $\mathrm{KSS} 4 / \mathrm{C}_{18} \mathrm{H}_{36}$ is shown in Fig. 4. One can see that the splitting $\Delta \nu_{1,2}(T)$ is practically constant in the temperature interval from $-100{ }^{\circ} \mathrm{C}$ to $T_{\text {bOrot }}$. When the beginning of the phase transition in the solid state $\left(T_{\text {bOrot }}\right)$ is reached, the splitting magnitude drastically decreases in two stages: from $T_{\text {bOrot }}$ to $T_{b m}$, and from $T_{b m}$ to $T_{m}$. A conclusion can be drawn that, when being cooled down to $-150{ }^{\circ} \mathrm{C}$, both bulk 1-octadecene and 1-octadecene in various matrices crystallize with the orthorhombic symmetry of the $\mathrm{Or}_{\text {crys }}$ cells. When the commencing temperature of the phase transition $T_{\mathrm{bOrot}}$ is attained, the phase transition into the orthorhombic rotationalcrystalline phase $\mathrm{Or}_{\mathrm{rot}}$ takes place. This transition is accompanied by a partial decrease of the Davydov splitting magnitude $\Delta \nu_{1,2}(T)$, because the azimuthal correlation between 1-octadecene molecules becomes partially lost. When the temperature $T_{b m}$ is reached, the splitting magnitude $\Delta \nu_{1,2}(T)$ sharply vanishes. This behavior testifies that the azimuthal correlation between the molecules becomes completely lost, i.e., the specimen undergoes the melting.

In Figs. 5 and 6, the temperature dependences of the shifts of the symmetric $\left(\nu_{s}\left(-\mathrm{CH}_{2}\right)\right.$, Fig. 5) and antisymmetric $\left(\nu_{\text {as }}\left(-\mathrm{CH}_{2}\right)\right.$, Fig. 6) valence vibration bands with respect to their positions at $-150{ }^{\circ} \mathrm{C}$ are exhibited for all examined specimens. The de-

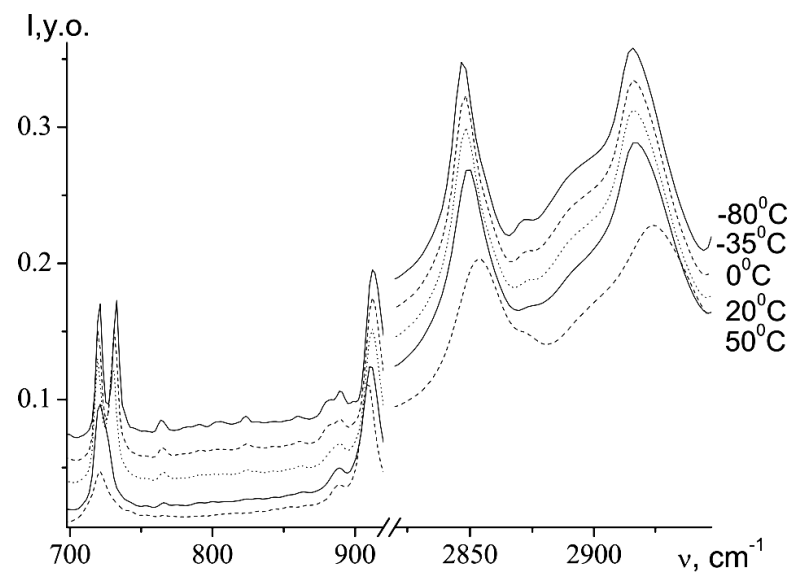

Fig. 3. Infrared transmission spectra of 1-octadecene at various temperatures

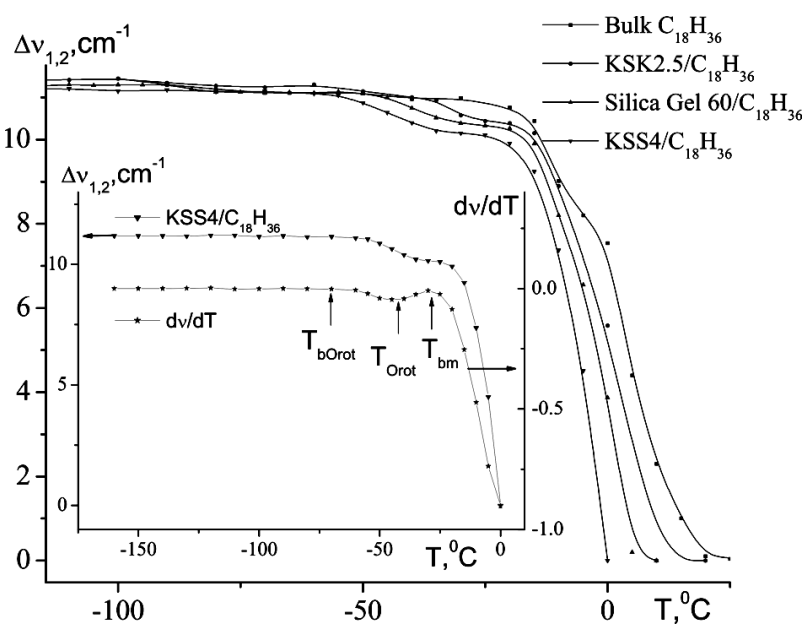

Fig. 4. Temperature dependences of the splitting $\Delta \nu_{1,2}(T)$ of the band of pendulum vibrations of $\mathrm{CH}_{2}$ groups in a vicinity of $\nu=720 \mathrm{~cm}^{-1}$ for bulk 1-octadecene and 1-octadecene in various matrices. The indicated temperature dependence for $\mathrm{KSS} 4 / \mathrm{C}_{18} \mathrm{H}_{36}$ and the temperature dependence of its derivative with respect to the temperature are shown in the inset

pendences demonstrate a few inflection points that coincide with the phase transition temperatures. To analyze the temperature behavior of the band position for symmetric and antisymmetric valence vibrations, we plotted the temperature dependences of the derivative $d \nu / d T$. The corresponding plots are shown for the specimens SilicaGel60/ $\mathrm{C}_{18} \mathrm{H}_{36}$ (Fig. 5) and KSK2.5 $/ \mathrm{C}_{18} \mathrm{H}_{36}$ (Fig. 6). Two maxima are observed in those dependences. One of them is associated with the phase transition in the solid state, and the other 


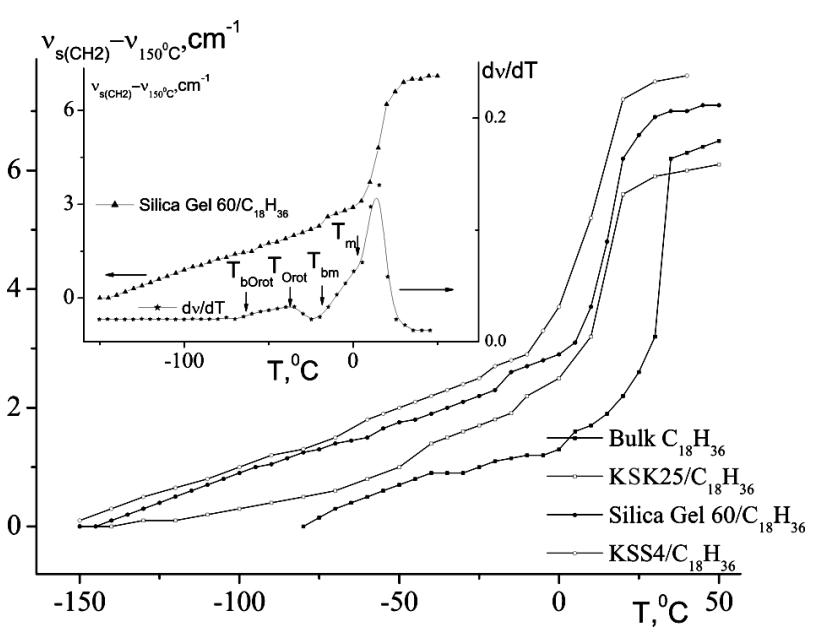

Fig. 5. Temperature dependences of the shift $\nu_{s}\left(-\mathrm{CH}_{2}\right)$ of the band of symmetric valence vibrations with respect to its position at $-150{ }^{\circ} \mathrm{C}$ for bulk 1-octadecene and 1-octadecene in various matrices. The indicated temperature dependence for SilicaGel60/ $\mathrm{C}_{18} \mathrm{H}_{36}$ and the temperature dependence of its derivative with respect to the temperature are shown in the inset

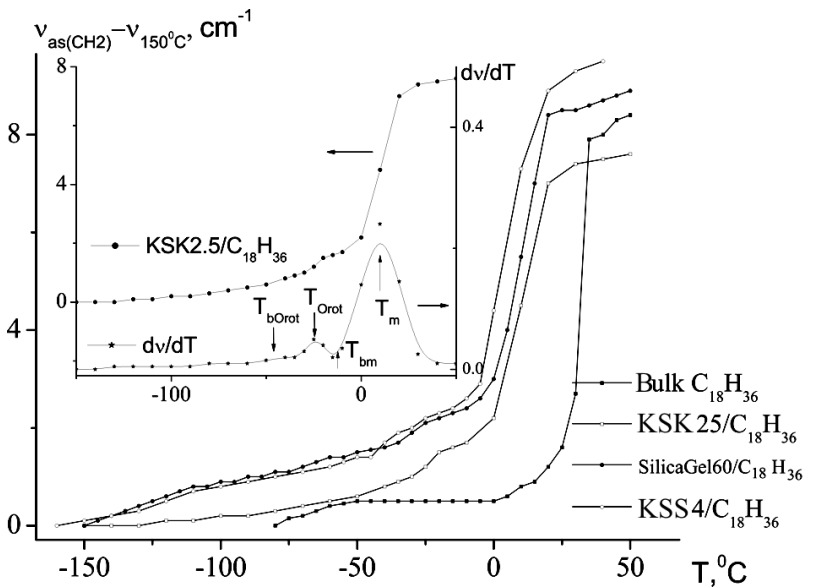

Fig. 6. Temperature dependences of the shift $\nu_{a} s\left(-\mathrm{CH}_{2}\right)$ of the band of antisymmetric valence vibrations with respect to its position at $-150{ }^{\circ} \mathrm{C}$ for bulk 1-octadecene and 1-octadecene in various matrices. The indicated temperature dependence for $\mathrm{KSK} 2.5 / \mathrm{C}_{18} \mathrm{H}_{36}$ and the temperature dependence of its derivative with respect to the temperature are shown in the inset

with the melting. All other specimens also demonstrated two phase transitions, whose temperatures decreased together with the pore size.

The band at $912 \mathrm{~cm}^{-1}$ (Fig. 3) is associated with deformational atomic vibrations of the end vinyl group. It is known [13] to be one of the most suitable

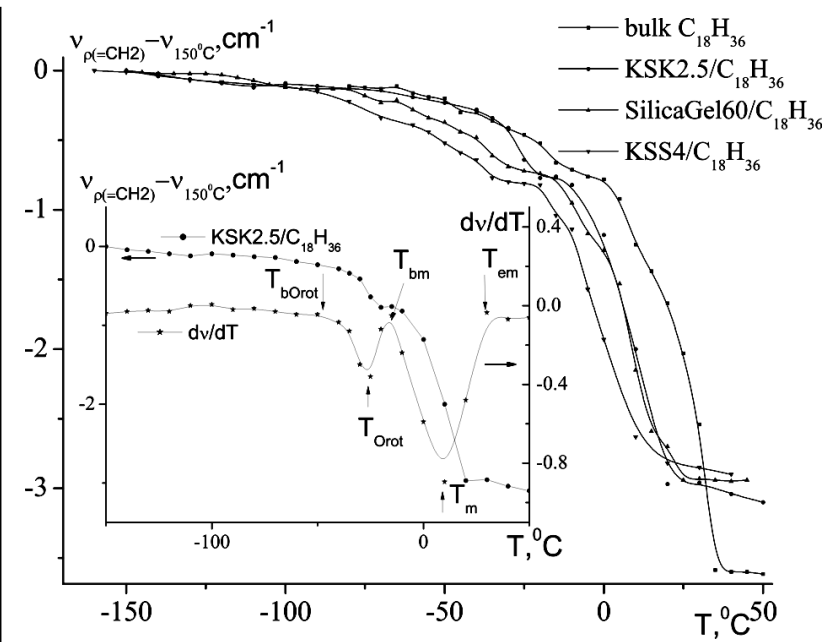

Fig. 7. Temperature dependences of the shift of the band of deformational vibrations of the double bond $-\mathrm{CH}=\mathrm{CH}_{2}$ with respect to its position at $-150{ }^{\circ} \mathrm{C}$ for bulk 1-octadecene and 1-octadecene in various matrices. The indicated temperature dependence for $\mathrm{KSK} 2.5 / \mathrm{C}_{18} \mathrm{H}_{36}$ and the temperature dependence of its derivative with respect to the temperature are shown in the inset

bands for studying the character of molecular motion in olefins. We plotted the temperature dependences of the shift of the band of deformation vibrations of the double bond $-\mathrm{CH}=\mathrm{CH}_{2}\left(\nu_{\rho\left(=\mathrm{CH}_{2}\right)}\right)$ with respect to its position at $-150{ }^{\circ} \mathrm{C}$ for bulk 1-octadecene and 1-octadecene in various matrices. In order to exactly determine the phase transition temperatures for 1-octadecene and 1-octadecene in various matrices, we also plotted the temperature dependences of the temperature derivative $d \nu / d T$ of the shift of the band of deformation vibrations of the double bond $-\mathrm{CH}=\mathrm{CH}_{2}$. For KSK2.5/ $\mathrm{C}_{18} \mathrm{H}_{36}$, this dependence is shown in Fig. 7. One can see that the band position practically is not changed within the temperature interval from $-100{ }^{\circ} \mathrm{C}$ to $T_{\text {borot }}$. When reaching the beginning of the phase transition $\left(T_{\mathrm{bOrot}}\right)$, the band position drastically decreases in two stages: from $T_{\text {bOrot }}$ to $T_{b m}$, and from $T_{b m}$ to $T_{m}$. In the same intervals, two minima are also observed in the dependences of the temperature derivative of the band position for deformational vibrations of the double bond $-\mathrm{CH}=\mathrm{CH}_{2}$. All other specimens also demonstrated two phase transitions, whose temperatures decreased together with the pore size.

The band at $1378 \mathrm{~cm}^{-1}$ is associated with umbrella vibrations of the end methyl group. This band

ISSN 2071-0194. Ukr. J. Phys. 2019. Vol. 64, No. 4 
is known $[15,16]$ to be also suitable for studying the character of molecular motion in aliphatic chains. The temperature dependences of the shift of the band of umbrella vibrations of the final methyl group $-\mathrm{CH}_{3}\left(\nu_{\delta\left(-\mathrm{CH}_{3}\right)}\right)$ with respect to its position at $-150{ }^{\circ} \mathrm{C}$ were plotted for 1-octadecene and 1 -octadecene in various matrices (Fig. 8). One can see that every dependence has a maximum in the temperature interval from $-150{ }^{\circ} \mathrm{C}$ to $T_{\text {borot }}$. At the temperature when the phase transition begins $\left(T_{\text {bOrot }}\right)$, the band shift magnitude $\Delta \nu_{\delta}\left(\mathrm{CH}_{3}\right)$ starts to drastically increase. This growth continues up to $T_{b m}$. After reaching a maximum value at $T_{b m}$, the value of $\Delta \nu_{\delta\left(\mathrm{CH}_{3}\right)}$ for the umbrella vibrations of the final methyl group decreases and has a minimum at $T_{m}$. As the temperature increases further, the magnitude of $\Delta \nu_{\delta}\left(\mathrm{CH}_{3}\right)$ grows monotonically.

\section{Discussion of Results}

By studying the infrared spectra of 1-octadecene in pores of porous silica gel, the temperatures of the solid-state phase transition, $T_{\text {Orot }}$, are determined. In our previous works $[12,17]$, it was shown that it is expedient to describe the open-porous systems, with porous silica gels belonging to them, by the ratio $S / V$ between the silica gel surface area $S$ and the silica gel pore volume $V$ rather than by the pore radius. Therefore, the dependences of the solid-phase transition temperature $T_{\text {Orot }}$ on this ratio are plotted for bulk 1-octadecene and 1-octadecene in various silica gel matrices (Fig. 9).

To describe the dependence of the solid-phase transition temperature $T_{\text {Orot }}$ on the $S / V$ ratio, we use the following formula obtained in our previous work [12]:

$T_{0}=T_{\infty}\left(1+\frac{\alpha_{B}\left(T_{\infty}\right)-\alpha_{A}\left(T_{\infty}\right)}{\Lambda} \frac{S}{V}\right)$

where $T_{\infty}$ is the temperature of the phase transition in a macroscopic-sized crystal; $T_{0}$ is the temperature of the phase transition for the crystalline substance in pores; $\alpha_{A}\left(T_{\infty}\right)$ and $\alpha_{B}\left(T_{\infty}\right)$ are the surface tension coefficients at the crystalline phase-matrix and rotational phase-matrix interfaces, respectively; and $\Lambda$ is the specific heat of the phase transition in a macroscopic-sized crystal. The experimental dependence $T_{\text {Orot }}(S / V)$ in Fig. 9 is approximated by formula (1), which gave us the values

$T_{\infty} \frac{\alpha_{B}\left(T_{\infty}\right)-\alpha_{A}\left(T_{\infty}\right)}{\Lambda}=25 \mathrm{Knm}$

ISSN 2071-0194. Ukr. J. Phys. 2019. Vol. 64, No. 4

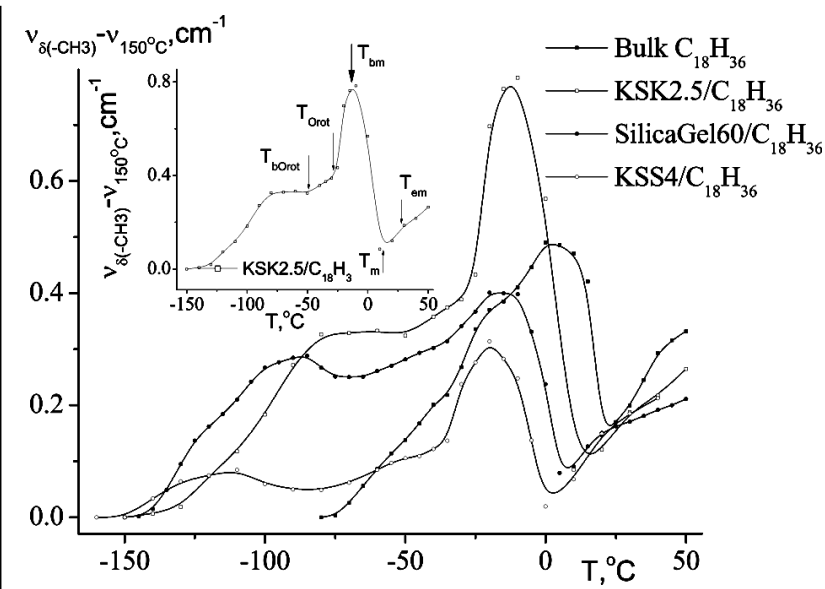

Fig. 8. Temperature dependences of the shift $\nu_{\delta}\left(-\mathrm{CH}_{3}\right)$ of the band of umbrella vibrations of the final methyl group $-\mathrm{CH}_{3}$ with respect to its position at $-150{ }^{\circ} \mathrm{C}$ for bulk 1 -octadecene and 1-octadecene in various matrices. The dependence for $\mathrm{KSK} 2.5 / \mathrm{C}_{18} \mathrm{H}_{36}$ is repeated in the inset

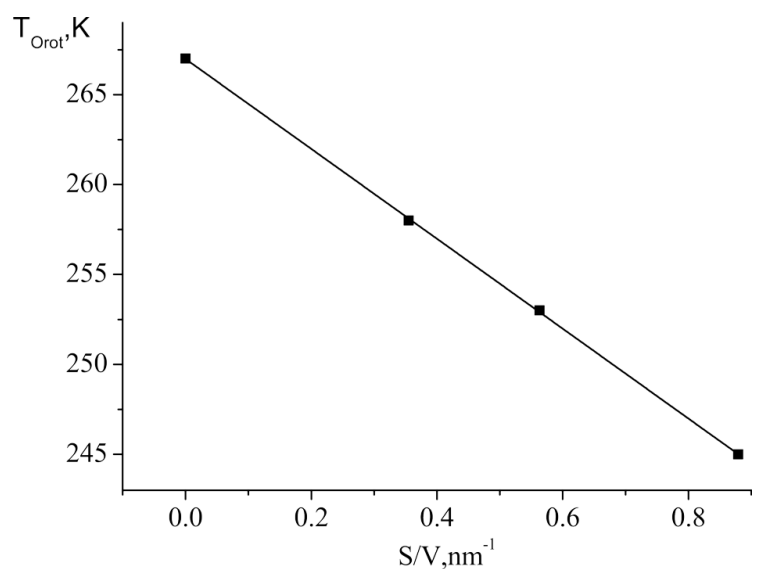

Fig. 9. Dependence of the temperature $T_{\text {Orot }}$ of the solidphase transition from the orthorhombic crystalline phase $\mathrm{Or}_{\text {crys }}$ into the orthorhombic rotational crystalline one $\mathrm{Or}_{\text {rot }}$ on the ratio $S / V$ for bulk 1-octadecene and 1-octadecene in various silica gel matrices

and $T_{\infty}=267 \mathrm{~K}$. The approximated temperature $T_{\infty}$ coincides with the temperature of the solid-phase transition in bulk 1-octadecene, i.e., the same 1octadecene crystalline structure is formed both in the bulk substance and in the pores of porous silica gel.

To find the surface tension difference $\alpha_{B}\left(T_{\infty}\right)-$ $-\alpha_{A}\left(T_{\infty}\right)$, we have to know the melting heat of bulk 1-octadecene. Experimentally (see Fig. 2), we obtained the specific heat value $\lambda=159.5 \mathrm{~kJ} / \mathrm{kg}$, which included the heat of the phase transition from the 


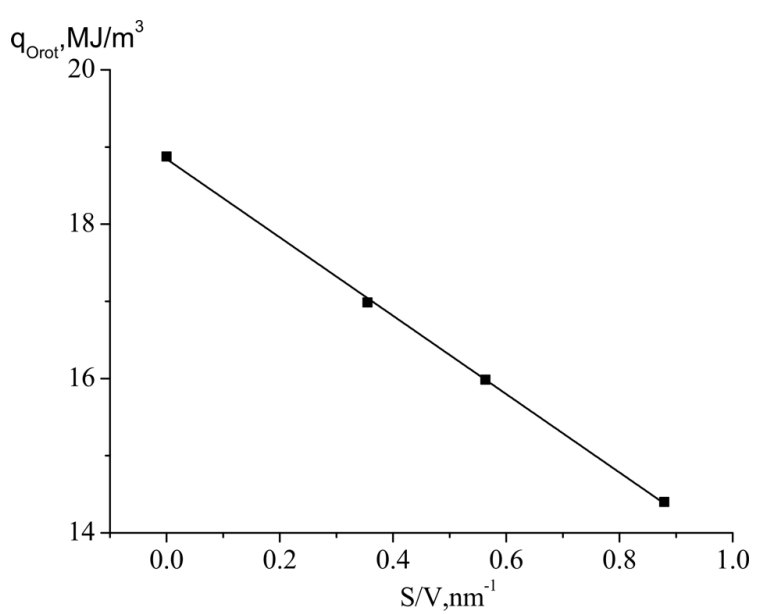

Fig. 10. Dependence of the heat $q_{\text {Orot }}$ of the phase transition from the orthorhombic crystalline phase into the orthorhombic rotational crystalline one of 1 -octadecene on the ratio $S / V$

orthorhombic crystalline phase to the orthorhombic rotational-crystalline one and the melting heat. Resolving the areas under the peaks in the temperature dependence of a heat flux for bulk 1-octadecene (Fig. 2), we found that the first peak included about $15 \%$ of the total area, whereas the second one about $85 \%$. Then, the specific heat of the solid-phase transition in bulk 1-octadecene amounts to $\lambda=24 \mathrm{~kJ} / \mathrm{kg}$.

In formula (1), $\Lambda$ is the phase transition heat per unit volume. Taking into account that the 1octadecene density $\rho=789 \mathrm{~kg} / \mathrm{m}^{3}$, the heat of the solid-phase transition per unit volume equals $\Lambda_{\text {Orot }}=$ $=19 \mathrm{MJ} / \mathrm{m}^{3}$, and the solid-phase transition temperature for bulk 1-octadecene equals $T_{\infty}=T_{\text {Orot }}=$ $=267 \mathrm{~K}$, we obtain that the difference between the surface tension coefficients at the crystalline phasematrix and rotational phase-matrix interfaces is

$\alpha_{B}\left(T_{\infty}\right)-\alpha_{A}\left(T_{\infty}\right)=-1.8 \times 10^{-3} \mathrm{~N} / \mathrm{m}$.

By comparing this value with the difference between the surface tension coefficients at the rotational phase-matrix and melt-matrix interfaces, which is equal to [12]

$\alpha_{B}\left(T_{\infty}\right)-\alpha_{A}\left(T_{\infty}\right)=-4.7 \times 10^{-3} \mathrm{~N} / \mathrm{m}$,

we see that the difference in the latter case is much larger.

Let us determine the specific heat of the solidphase transition for 1-octadecene in various porous silica gel matrices. From the experiment, we obtain the values of the specific heat for 1-octadecene in various porous silica gel matrices, which include the specific heat of the phase transition from the orthorhombic crystalline phase to the orthorhombic-rotationalcrystalline one and the specific heat of the melting. To resolve the contributions from those transitions, we assume that their relative contribution is the same as was in the case of bulk 1-octadecene $(15 \%$ and $85 \%$, Fig. 2). With regard for the mass of 1-octadecene in the porous matrix (Table 2), we can plot the dependence of the solid-phase transition heat per unit volume of 1-octadecene on the ratio $S / V$ (Fig. 10).

To describe the dependence of the solid-phase transition heat $q_{\text {Orot }}$ on the ratio $S / V$, we use the following formula obtained in our previous work [12]]:

$q=\Lambda-T_{\infty}\left[\frac{\partial \alpha_{B}}{\partial T}\left(T_{\infty}\right)-\frac{\partial \alpha_{A}}{\partial T}\left(T_{\infty}\right)\right] \frac{S}{V}$.

Here, the parameters $T_{\infty}$ and $\Lambda$ are the same as in formula (1), and the derivatives $\frac{\partial \alpha_{A}}{\partial T}$ and $\frac{\partial \alpha_{B}}{\partial T}$ are the surface entropies at the crystalline phase--matrix and rotational phase-matrix interfaces, respectively. By approximating the temperature dependence of the heat $q_{\text {Orot }}(S / V)$ (see Fig. 10) using formula (2), we obtain the value

$\frac{\partial \alpha_{B}}{\partial T}\left(T_{\infty}\right)-\frac{\partial \alpha_{A}}{\partial T}\left(T_{\infty}\right)=-0.2 \times 10^{-3} \mathrm{~N} / \mathrm{mK}$.

By comparing it with the surface entropy difference between the rotational phase-matrix and meltmatrix interfaces,

$\frac{\partial \alpha_{B}}{\partial T}\left(T_{\infty}\right)-\frac{\partial \alpha_{A}}{\partial T}\left(T_{\infty}\right)=-0.9 \times 10^{-3} \mathrm{~N} / \mathrm{mK}$,

one can see that the difference between the surface entropies of the phases at the melting is much larger than the corresponding difference at the solid-state transition.

Therefore, the processing of obtained experimental data enabled us to calculate both the difference between the surface energies and the difference between the surface entropies of the phases, which makes it possible to determine the energy parameters of the surface layer, when the pore surface is modified by various functional groups.

\section{Conclusions}

The structure of 1-octadecene crystals that are formed in silica gel pores is the same as in bulk 1-

ISSN 2071-0194. Ukr. J. Phys. 2019. Vol. 64, No. 4 
octadecene. Both the difference between the surface tensions and the difference between the surface entropies of the phases at the melting are larger than the corresponding differences at the phase transition from the orthorhombic crystalline phase into the orthorhombic rotational-crystalline one.

1. P. Huber. Soft matter in hard confinement: phase transition thermodynamics, structure, texture, diffusion and flow in nanoporous media. J. Phys.: Condens. Matter 27, 103102 (2015).

2. Q. Jiang, M.D. Ward. Crystallization under nanoscale confinement. Chem. Soc. Rev. 43, 2066 (2014).

3. M. Sliwinska-Bartkowiak, A. Sterczynska, Y. Long, K.E. Gubbins. Influence of microroughness on the wetting properties of nano-porous silica matrices. Mol. Phys. 112, 2365 (2014)

4. J. da Silva Buriti, M.E.V. Barreto, K.O. Santos, M.V.L. Fook. Thermal, morphological, spectroscopic and biological study of chitosan, hydroxyapatite and wollastonite biocomposites. J. Therm. Anal. Calorim. 134, 1521 (2018).

5. Dongqing Wang, Jian Sui, Di Qi, Shuping Deng, Yongteng Wei, Xin Wang, Xiao Zheng Lan. Phase transition of docosane in nanopores. J. Therm. Anal. Calorim. 135, 2869 (2018).

6. K. Jiang, B. Xie, D. Fu, F. Luo, G. Liu, Y. Su, D. Wang. Solid-solid phase transition of n-alkanes in multiple nanoscale confinement. J. Phys. Chem. B 114, 1388 (2009).

7. K. Nozaki, M. Hikosaka. Mechanism of primary nucleation and origin of hysteresis in the rotator phase transition of an odd n-alkane. J. Mater. Sci. 35, 1239 (2000).

8. A.B. Herhold, H.E. King, Jr, E.B. Sirota. A vanishing nucleation barrier for the n-alkane rotator-to-crystal transformation. J. Chem. Phys. 116, 9036 (2002).

9. H. Gang, O. Gang, H.H. Shao et al. Rotator phases and surface crystallization in eicosene J. Phys. Chem. B 102, 2754 (1998).

10. O.M. Alekseev, S.O. Alekseev, L.A. Bulavin, M.M. Lazarenko, O.M. Maiko. Phase transitions in chain molecular polycrystals of 1-octadecene. Ukr. J. Phys. 53, 882 (2008).
11. M.M. Lazarenko, A.N. Alekseev, S.A. Alekseev, Yu.E. Grabovsky, M.V. Lazarenko. Phase transitions of some aliphatic molecular crystals in confined space. Khim. Fiz. Tekhnol. Poverkhn. 2, 128 (2011) (in Ukrainian).

12. L.A. Bulavin, O.M. Alekseev, Y.F. Zabashta, M.M. Lazarenko. Phase equilibrium, thermodynamic limit, and melting temperature in nanocrystals. Ukr. J. Phys. 63, 1036 (2018).

13. L.M. Babkov, G.A. Puchkovskaya, S.P. Makarenko, T.A. Gavrilko. IR Spectroscopy of Molecular Crystals with Hydrogen Bonds (Naukova Dumka, 1989) (in Russian).

14. E.N. Kotelnikova, S.K. Filatov. Crystal Chemistry of Paraffins (Zhurnal-Neva, 2002) (in Russian).

15. M. Del Zoppo, G. Zerbi. Surface melting in crystalline polymethylene systems. Polymer 31, 658 (1990).

16. S.Y. Tkachev, O.M. Alekseev, M.M. Lazarenko, M.V. Lazarenko et al. Topological solitons in branched aliphatic molecules. Mol. Cryst. Liq. Cryst. 665, 166 (2018).

17. L.A. Bulavin, O.M. Alekseev, Y.F. Zabashta, M.M. Lazarenko. Melting thermodynamics of nanocrystals. J. Phys. Stud. 22, 2601 (2018).

Received 18.01.19.

Translated from Ukrainian by O.I. Voitenko

О.М. Алексеєв, С.О. Алексеєв,

Ю.Ф. Забашта, М.М. Лазаренко, К.І. Гнатюк,

М.В. Лазаренко, Р.В. Дінжос, М.С. Сімеонов

ВПЛИВ ВІДКРИТО-ПОРИСТОЇ СИСТЕМИ

НА ТВЕРДОФАЗНИЙ ПЕРЕХІД В 1-ОКТАДЕЦЕНІ

$\mathrm{P}$ е $з$ ю м е

За допомогою дифереціальноскануючої калориметрії та IЧспектрів при різних температурах проводились дослідження твердофазного переходу в системі силікагель - 1-октадецен. Використовувались силікагелі марок KSK 2.5, Silica Gel 60, KSS 4, які мають різні характеристики поверхні. Показано, що температура твердофазного переходу систем силікагель - 1-октадецен лінійно залежить від відношення площі до об'єму пор. За допомогою термодинамічної моделі плавлення кристалів у порах розраховані енергетичні характеристики поверхневого шару нанокристалів. 